\title{
Electrochemical Determination of Dihydrocodeine in Pharmaceuticals
}

\author{
J. M. P. J. Garrido, C. Delerue-Matos, F. Borges, T . \\ R. A. Macedo and A. M. Oliveira-Brett
}

\begin{abstract}
Two analytical methods for the quality control of dihydrocodeine in commercial pharmaceutical formulations have been developed and compared with reference methods: a square wave voltammetric (SWV) method and a flow injection analysis system with electrochemical detection (FIA-EC). The electrochemical methods proposed
\end{abstract}


were successfully applied to the determination of dihydrocodeine in pharmaceutical tablets and in oral solutions. These methods do not require any pretreatment of the samples, the formulation only being dissolved in a suitable electrolyte. Validation of the methods showed it to be precise, accurate and linear over the concentration range of analysis. The automatic procedure based on a flow injection analysis manifold allows a sampling rate of 115 determinations per hour.

Key Words: Dihydrocodeine; Square wave voltammetry; Flow injection analysis with electrochemical detection; FIA.

\section{INTRODUCTION}

Dihydrocodeine (DHC) is a semisynthetic opioid that is frequently used as a moderately potent analgesic and antitussive agent (Fig. 1). Although dihydrocodeine is structurally related to the natural occurring opioid codeine it has 2-4 times more potent analgesic activity. Dihydrocodeine has been nominated by the World Health Organisation as a second-step drug in therapeutic strategy for cancer pain relief. ${ }^{[1]}$ Furthermore, doses up to $2500 \mathrm{mg}$ per day are prescribed in substitution therapy for heroin drug addicted people.

Despite dihydrocodeine being used as active substance in a variety of pharmaceutical preparations available in the market, it is surprising that few analytical methods were proposed for its determination.

Most of the methodologies proposed for dihydrocodeine determination, namely GC ${ }^{[2,3]}$ HPLC, ${ }^{[4,5]}$ capillary electrophoresis ${ }^{[6]}$ and immunological assays, ${ }^{[6,7]}$ have been used for pharmacokinetic studies or forensic screening in biological samples such as plasma, blood or urine. Assay

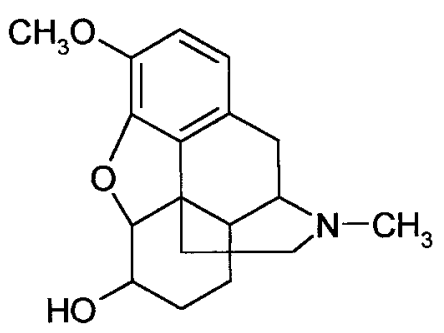

Figure 1. Structure of dihydrocodeine. 
methods reported in the British ${ }^{[8]}$ and United States ${ }^{[9]}$ Pharmacopoeias for dihydrocodeine determination in pharmaceutical preparations are based on extraction of the base followed by nonaqueous titrimetry and in HPLC, the last technique also being the most proposed in the literature for quantification of this compound. ${ }^{[10,11]}$

Electroanalytical techniques have proved for a long time to be very useful methodologies due to their sensitivity and low operating costs. Although some of the HPLC methods proposed use an electrochemical detector ${ }^{[4]}$ few electrochemical studies concerning dihydrocodeine have been reported. ${ }^{[12]}$ Indeed, this could be due to the fact that until the middle $80 \mathrm{~s}$ it was stated in the literature that codeine, the starting material used to produce dihydrocodeine after reduction of the 7,8-double bond, is devoid of electroactivity.

In order to develop a method adequate for routine analysis that could surpass some of the drawbacks of the proposed methodologies, e.g., time consuming and with intensive solvent usage, sophisticated instruments and training, an electrochemical study of the behavior of dihydrocodeine at a glassy carbon electrode has been carried out. The results obtained enabled the development of a square-wave voltammetric (SWV) method, and of an alternative analytical method that combines the advantages of amperometric detection with those of flow injection analysis (FIA-EC). Both methods were applied to the determination of dihydrocodeine in commercial pharmaceutical preparations available in the market without submitting the samples to any pretreatment other than dissolution.

\section{MATERIALS AND METHODS}

\subsection{Equipment}

Voltammetric measurements were carried out using a 663 VA Metrohm cell containing a glassy carbon working electrode (Metrohm, Switzerland, $d=2.0 \mathrm{~mm})$, a glassy carbon rod counter electrode (Metrohm, Switzerland) and an $\mathrm{Ag} / \mathrm{AgCl}(3 \mathrm{M} \mathrm{KCl})$ reference electrode (Metrohm, Switzerland) attached to an Autolab PSTAT 10 potentiostat/galvanostat running with GPES software (EcoChimie, Netherlands).

The FIA manifold (Fig. 4) consists of a Gilson Minipuls 3 peristaltic pump (Gilson, France) to propel the solutions, a Rheodyne 5020 valve (Rheodyne, Berkely, CA) to inject the solutions and an electrochemical detector system consisting of a VA 641 Metrohm detector and a 656 Metrohm electrochemical wall-jet cell (Metrohm, Switzerland). This cell 
contains three electrodes, a Metrohm glassy carbon working electrode, a Metrohm gold auxiliary electrode and a Metrohm $\mathrm{Ag} / \mathrm{AgCl}(3 \mathrm{M} \mathrm{KCl})$ reference electrode. Omnifit Teflon tubing $(0.8 \mathrm{~mm}$ i.d.) (Omnifit, Cambridge, UK) and Gilson end fittings as well as homemade dampers drilled from perspex ${ }^{[13]}$ were used to connect the manifold components. A Kipp \& Zonen (model BD 112) data recorder was used to register the analytical signals (Kipp \& Zonen, Netherlands).

The glassy carbon working electrodes were manually cleaned and polished on an abrasive surface every day, with $1 \mu \mathrm{m}$ particle size $\mathrm{Al}_{2} \mathrm{O}_{3}$ (BDH, England) and then rinsed carefully with deionized water.

A Metrohm E520 pH-meter with glass electrode was used for the $\mathrm{pH}$ measurements (Metrohm, Switzerland).

For the HPLC reference method, ${ }^{[8,9]}$ a Sykam model A 1210 liquid chromatograph (Sykam, Germany), equipped with an UV detector $(\lambda=284 \mathrm{~nm})$ model 3200 was used. Separation of sample components was accomplished using a Nucleosil $120-5$ C18 column $(250 \times 4 \mathrm{~mm}$, $5 \mu \mathrm{m}$ particle size, Macherey-Nagel, Germany). The analysis was carried out at room temperature using $0.01 \mathrm{M}$ sodium acetate and $0.005 \mathrm{M}$ dioctyl sodium sulphosuccinate mixed in 60 volumes of methanol plus 40 volumes of water as mobile phase, at a flow rate of $1.5 \mathrm{~mL}$ per minute, the $\mathrm{pH}$ of the mixture being adjusted to 5.5 with glacial acetic acid.

\subsection{Chemicals and Solutions}

Dihydrocodeine bitartrate was kindly provided by Knoll Lusitana (Prior Velho, Portugal). Analytical grade reagents purchased from Merck (Darmstadt, Germany) were used without additional purification. Deionised water (conductivity $<0.1 \mu \mathrm{S} \mathrm{cm}^{-1}$ ) was used throughout. The pH 3 acetate buffer used for voltammetric determinations was prepared by dilution to $100 \mathrm{~mL}$ of $3.7 \mathrm{~mL}$ of $0.2 \mathrm{M}$ sodium acetate and $46.3 \mathrm{~mL}$ of $0.2 \mathrm{M}$ acetic acid. The $\mathrm{pH} 6$ supporting electrolyte used as carrier in the FIA system was prepared by dilution to $100 \mathrm{~mL}$ of $6.2 \mathrm{~mL}$ of $0.2 \mathrm{M}$ dipotassium hydrogen phosphate and $43.8 \mathrm{~mL}$ of $0.2 \mathrm{M}$ potassium dihydrogen phosphate. In the HPLC reference method all the solvents used, purchased from Merck (Darmstadt, Germany), were of HPLC grade. Prior to use, the solvents were filtered and the air removed with helium.

The determination of dihydrocodeine in commercial formulations was carried out on Didor Continus ${ }^{\circledR}$ tablets (Asta Medica, Lisbon, Portugal), Paracodina ${ }^{\circledR}$ tablets (Knoll, Prior Velho, Portugal) and

Paracodina $\mathrm{N}^{\circledR}$ oral solution (Knoll, Prior Velho, Portugal); for the nominal content of the labeled dihydrocodeine see Table 3. 


\subsection{Standard and Sample Solutions}

A standard stock solution of dihydrocodeine bitartrate at a concentration of $1 \mathrm{mM}$ was prepared by dissolving the appropriate amount of dihydrocodeine bitartrate in $0.01 \mathrm{M} \mathrm{HClO}_{4}$.

In the voltammetric method accurate volumes of the stock standard solution were added, in the voltammetric cell, to $\mathrm{pH} 3$ buffer solution in order to obtain dihydrocodeine concentrations between 40 and $140 \mu \mathrm{M}$. For the FIA system, more dilute solutions, between 7 and $50 \mu \mathrm{M}$, were prepared by appropriate dilution of the stock solution with $\mathrm{pH} 6$ supporting electrolyte. All solutions were prepared daily.

Preparation of samples for analysis was carried out as follows: ten tablets were weighed to determine the average tablet weight and finely powdered in an agate mortar. An accurately weighed powder sample, appropriate to obtain a concentration of dihydrocodeine within the calibration curve range, was carefully dissolved in acetate buffer $\mathrm{pH} 3$ (SW determination) or phosphate buffer $\mathrm{pH} 6$ (FIA determination).

A suitable volume of oral solution was just diluted with buffer solution to achieve the appropriate concentration.

\subsection{Validation of the Analytical Methods}

Once the square wave and flow injection experimental conditions were established methods for validation were performed.

The linearity of the methods was determined by building calibration curves. For the square wave voltammetric method a six-point calibration curve was set up by plotting peak currents of the oxidation peak against dihydrocodeine standard solution concentrations, in the $40-140 \mu \mathrm{M}$ range. In the flow injection method analyses were performed by injecting dihydrocodeine standard solutions in the $7-50 \mu \mathrm{M}$ range. A six-point calibration curve was set up by plotting the values of dihydrocodeine peak heights against dihydrocodeine concentrations.

The limit of quantification (LOQ) and the limit of detection (LOD) were calculated according to USP XXIV guidelines. ${ }^{[9]} \mathrm{A} \mathrm{S} / \mathrm{N}$ ratio of ten and three were used respectively.

Method precision was determined by replicate determinations of three different concentration levels of dihydrocodeine. Intraday repeatability was studied by carrying out five measurements for each level on the same day. Interday repeatability was obtained by performing three determinations for each concentration on five consecutive days. 
The accuracy of the proposed methods was determined by comparing the results obtained with those from reference methods. ${ }^{[8,9]}$ A reversedphase HPLC with UV detection and a nonaqueous titrimetric method were used for oral solution and tablets, respectively.

\section{RESULTS AND DISCUSSION}

\subsection{Effect of $\mathbf{p H}$}

The electrochemical oxidation of dihydrocodeine at a glassy carbon electrode was studied over a very wide $\mathrm{pH}$ range by differential pulse voltammetry (Fig. 2). The oxidation always occurs at very high positive potentials, making impossible the use of platinum or gold as working electrodes.

The oxidation mechanism of dihydrocodeine is complex with adsorption occurring at the electrode surface and is $\mathrm{pH}$ dependent. At very acidic $\mathrm{pH}$ only one oxidation peak can be observed. For $\mathrm{pH}$ between 3 and 7 two oxidation peaks are seen and at $\mathrm{pH}$ above 7 three peaks can be detected. The position of all peaks was $\mathrm{pH}$ dependent. Due to the very

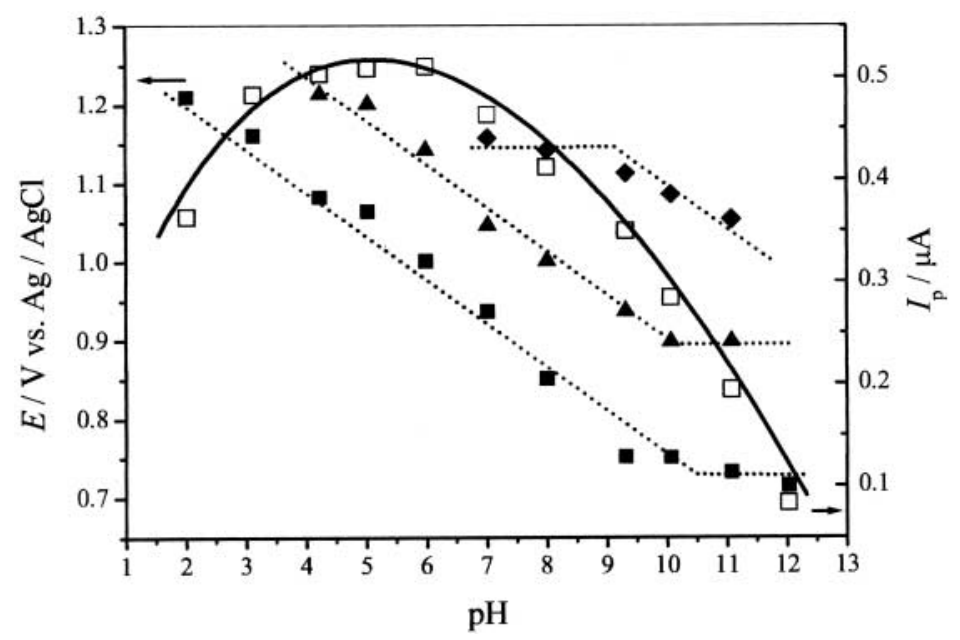

Figure 2. Plots of $E_{p}$ (filled symbols) and $I_{p}$ (open symbol) vs. pH from differential pulse voltammograms of $0.1 \mathrm{mM}$ solutions of dihydrocodeine in $0.2 \mathrm{M}$ ionic strength buffer electrolyte: $(\boldsymbol{\square} \square$ ) first peak, $(\boldsymbol{\Delta})$, second peak, $(\diamond)$ third peak. Scan rate $5 \mathrm{mV} \mathrm{s}^{-1}$. 
high positive potentials necessary, detection of the peaks with higher potentials is limited by solvent evolution. Considering the current for the first oxidation peak, it reaches a maximum value at $\mathrm{pH}=6$ (Fig. 2).

\subsection{Square Wave Voltammetric Method}

Square wave voltammetry (SWV) was used to develop a voltammetric method for the determination of dihydrocodeine in commercial pharmaceutical preparations, since this pulse voltammetric mode is highly expeditious and sensitive. As seen in Fig. 2, the oxidation of dihydrocodeine is a complex mechanism and three oxidation peaks can be observed at high $\mathrm{pH}$. Although the highest peak current intensity was observed at $\mathrm{pH} 6$, in order to minimize the eventual fouling of the electrode surface by adsorption of the products of the possible three oxidation processes a buffer supporting electrolyte of $\mathrm{pH} 3$ was selected for subsequent studies since at this $\mathrm{pH}$ only one peak appears (Fig. 3).

The influence of the square wave frequency $(f)$, pulse amplitude $\left(E_{s}\right)$ and ionic strength $(I)$ was assessed with a view to optimization of the experimental conditions. Optimized parameters found were $f=150 \mathrm{~Hz}$, $E_{s}=50 \mathrm{mV}$ and $I=0.2 \mathrm{M}$, and good linearity was obtained in the

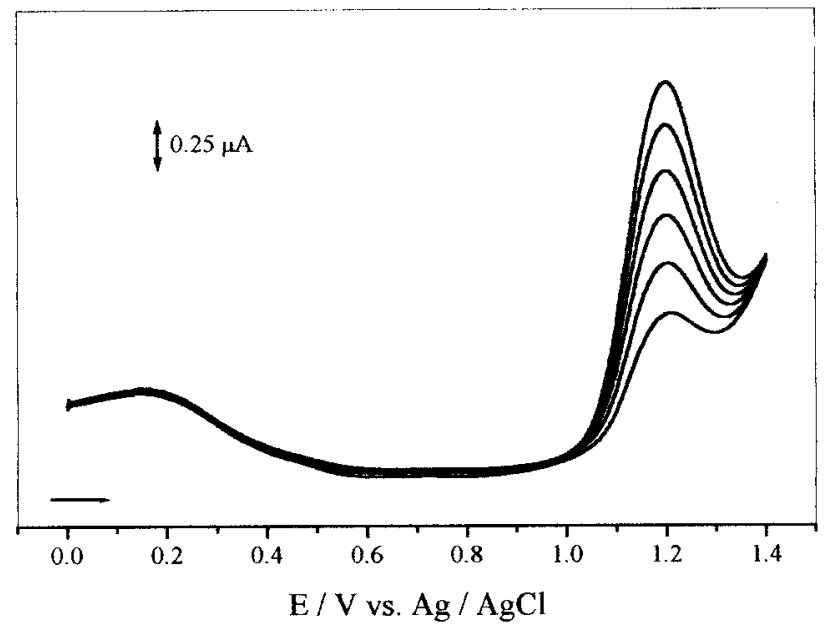

Figure 3. Successive square wave voltammograms, in pH $30.2 \mathrm{M}$ buffer electrolyte, of dihydrocodeine standard solutions: 40.6, 60.6, 80.4, 100, 119 and $139 \mu \mathrm{M}$. Frequency $150 \mathrm{~Hz}$; pulse amplitude $50 \mathrm{mV}$. 
Table 1. Linearity range, quantification and detection limits and intraday and interday repeatability for determination of dihydrocodeine using the square wave voltammetric method (SWV).

\begin{tabular}{|c|c|}
\hline & SWV \\
\hline Linearity range $(\mu \mathrm{M})$ & $40-140$ \\
\hline $\mathrm{Slope}^{\mathrm{a}} \pm \mathrm{RSD} \%$ & $1.7 \times 10^{-2} \pm 1.4$ \\
\hline Intercept $^{\mathrm{a}} \pm \mathrm{RSD} \%$ & $2.0 \times 10^{-7} \pm 0.9$ \\
\hline \multicolumn{2}{|c|}{ Intraday precision $\left(\mathrm{RSD}^{\circ}\right)^{\mathrm{b}}$} \\
\hline $40 \mu \mathrm{M}$ & 1.6 \\
\hline $80 \mu \mathrm{M}$ & 2.1 \\
\hline $140 \mu \mathrm{M}$ & 1.2 \\
\hline \multicolumn{2}{|c|}{ Interday precision $\left(\mathrm{RSD}^{\circ}\right)^{\mathrm{b}}$} \\
\hline $40 \mu \mathrm{M}$ & 2.9 \\
\hline $80 \mu \mathrm{M}$ & 2.5 \\
\hline $140 \mu \mathrm{M}$ & 1.8 \\
\hline LOQ $(\mu \mathrm{M})$ & 14 \\
\hline $\mathrm{LOD}(\mu \mathrm{M})$ & 4 \\
\hline
\end{tabular}

${ }^{\mathrm{a}} \operatorname{Mean}(n=3)$.

${ }^{\mathrm{b}}$ Mean $(n=5)$.

40-140 $\mu \mathrm{M}$ dihydrocodeine concentration range (Fig. 3). The linearity equation obtained by means of the least square method was $y=1.7 \times 10^{-2} x+2.0 \times 10^{-7}$ with a correlation coefficient higher than 0.999 . The coefficient of variation of the slope and intercept was 1.4 and $0.9 \%$, respectively (Table 1 ). The LOQ and LOD, calculated according to USP XXIV guidelines ${ }^{[9]}$ were 14 and $4 \mu \mathrm{M}$, respectively. Precision assays were carried out at three levels $(40,80$ and $140 \mu \mathrm{M})$ and the results were good; the RSD\% values obtained ranged from 1.2 to $2.1 \%$ for repeatability (intraday precision) and from 1.8 to $2.9 \%$ for intermediate (interday) precision (Table 1).

\subsection{Flow Injection Analysis with Electrochemical Detection}

A flow injection analysis manifold with electrochemical detection (FIA-EC) system was developed in order to quantify dihydrocodeine in pharmaceutical preparations, optimizing each variable parameter separately and fixing the remainder. The aim was finding the best conditions in terms of sensitivity, reproducibility and sampling rate. Hence, a single channel manifold was set up (Fig. 4) and the influences of the working 


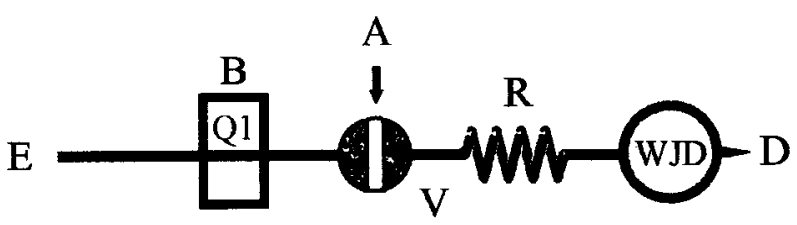

Figure 4. Flow injection analysis manifold used for dihydrocodeine determination: A-sample, B-peristaltic pump, E-inlet for $\mathrm{pH} 6 \mathrm{~K}_{2} \mathrm{HPO}_{4} / \mathrm{KH}_{2} \mathrm{PO}_{4}$ buffer supporting electrolyte, $\mathrm{Q} 1$ - flow rate $2.4 \mathrm{~mL} \mathrm{~min}^{-1}, \mathrm{~V}$-injection valve $(78 \mu \mathrm{L}), \mathrm{R}$ - mixing coil $(30 \mathrm{~cm}), \mathrm{WJD}$ - wall-jet electrochemical detector, Doutlet for waste.

electrode potential, the flow rate $(\mathrm{Q} 1)$, the injection volume $(A)$ and the length of the reactor $(R)$ were assessed separately. In these experiments to determine the best working conditions of the FIA manifold a $100 \mu \mathrm{M}$ solution of dihydrocodeine was used.

The use of low concentrations in this flow system and the brief contact between the sample and the electrode surface drastically reduce the possibility of fouling caused by adsorption processes. Since it was known from the differential pulse voltammetric study that the highest current is obtained for $\mathrm{pH} 6$ (Fig. 2) it was decided to use this as the buffer supporting electrolyte for further studies.

To optimize the working electrode potential the variation of the current peak height with applied potential in the range +1.2 to $+1.5 \mathrm{~V}$ was studied. The highest value for the current peak was obtained for $+1.3 \mathrm{~V}$ and so this was used subsequently.

The best flow rate depends on the characteristics of the electrochemical detector whose small dead volume (approximately $1 \mu \mathrm{L}^{[14]}$ ) does not permit the use of very high flow rates. Our studies showed that too high flow rates lead to high pressures inside the system, causing irreproducible signals, and low flow rates compromised sampling rates. Taking this into account, the value of $2.4 \mathrm{~mL} \mathrm{~min}^{-1}$ at the entry of the detector was chosen.

Once the flow rate had been optimised, the best injection volume was established by testing different loops, constructed with the same Teflon tubing used for the other parts of the system $(0.8 \mathrm{~mm}$ i.d.), with lengths between 5 and $20 \mathrm{~cm}$. A $10 \mathrm{~cm}$ loop was chosen since larger loops reduced the sampling rate whereas smaller loops produced less reproducible analytical signals. The injection volume corresponding to this $10 \mathrm{~cm}$ loop was accurately determined by titration of a solution of known concentration and was $78 \mu \mathrm{L} .^{[15]}$ 
The optimization of the system concluded with the optimization of the reactor length $(R)$ between the injection valve and the detector. Different lengths of reactor (teflon tubing $0.8 \mathrm{~mm}$ i.d.) were tested, between 20 and $40 \mathrm{~cm}, 30 \mathrm{~cm}$ being selected regarding reproducibility, sensitivity and sampling rate.

The flow injection methodology developed led to very reproducible results (Fig. 5). Using these optimized parameters a calibration curve was set up with standard solutions in the $7-50 \mu \mathrm{M}$ concentration range. The least-square regression equation was $y=9.3 \times 10 x^{4}+0.4$ with a correlation coefficient higher than 0.999 . The coefficient of variation of the slope was $1.1 \%$ and of the intercept $0.6 \%$ (Table 2). The LOQ obtained was $3 \mu \mathrm{M}$ and the LOD was $1 \mu \mathrm{M}$. Precision assays were carried out at three levels $(7,20$ and $50 \mu \mathrm{M})$ and the results were very good; RSD\% values ranged from 0.5 to $1.0 \%$ for repeatability and from 0.9 to $1.8 \%$ for intermediate precision (Table 2). This FIA manifold enabled sampling rates of about 115 samples per hour.

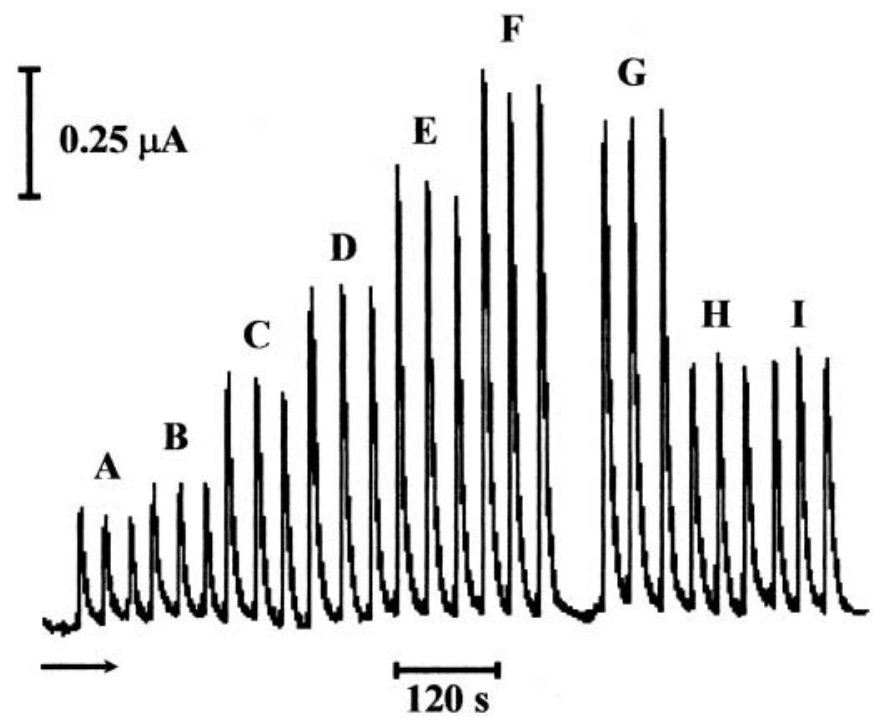

Figure 5. Flow injection analysis with electrochemical detection of $\mu \mathrm{M}$ dihydrocodeine standard solutions: A - 6.64, B-9.97, C-19.9, D-29.9, E-39.9, F49.8, and pharmaceutical samples: $\mathrm{G}$-Didor, $\mathrm{H}$-Paracodina and I-Paracodina $\mathrm{N}$, under the experimental conditions described. 
Table 2. Linearity range, quantification and detection limits and intraday and interday repeatability for determination of dihydrocodeine using FIA with electrochemical detection system (FIA-EC).

\begin{tabular}{|c|c|}
\hline & FIA-EC \\
\hline Linearity range $(\mu \mathrm{M})$ & $7-50$ \\
\hline Slope $^{\mathrm{a}} \pm \mathrm{RSD} \%$ & $9.3 \times 10^{4} \pm 1.1$ \\
\hline Intercept $^{\mathrm{a}} \pm \mathrm{RSD} \%$ & $0.4 \pm 0.6$ \\
\hline \multicolumn{2}{|c|}{ Intraday precision $\left(\mathrm{RSD}_{0} \%\right)^{\mathrm{b}}$} \\
\hline $7 \mu \mathrm{M}$ & 1.0 \\
\hline $20 \mu \mathrm{M}$ & 0.8 \\
\hline $50 \mu \mathrm{M}$ & 0.5 \\
\hline \multicolumn{2}{|c|}{ Interday precision $\left(\mathrm{RSD}^{\circ}\right)^{\mathrm{b}}$} \\
\hline $7 \mu \mathrm{M}$ & 1.8 \\
\hline $20 \mu \mathrm{M}$ & 1.6 \\
\hline $50 \mu \mathrm{M}$ & 0.9 \\
\hline LOQ $(\mu \mathrm{M})$ & 3 \\
\hline $\mathrm{LOD}(\mu \mathrm{M})$ & 1 \\
\hline
\end{tabular}

${ }^{\mathrm{a}}$ Mean $(n=3)$.

${ }^{\mathrm{b}}$ Mean $(n=5)$.

\subsection{Determination of Dihydrocodeine in Pharmaceutical Preparations}

Dihydrocodeine is orally administered either in liquid or solid form. There are three commercial pharmaceutical preparations available in Portugal containing dihydrocodeine (Table 3) two in the form of tablets and one as oral solution. In all these preparations dihydrocodeine is the only active substance and the other components do not give a significant signal under the experimental electrochemical conditions used in the SWV and FIA-EC determinations.

For the voltammetric method, SW voltammograms were recorded for different dihydrocodeine standards in the concentration interval 40-140 $\mu \mathrm{M}$ (Fig. 3) and for the commercial samples.

The FIA-EC system was calibrated by three replicate injections of six dihydrocodeine standards in a concentration range between 7 and $50 \mu \mathrm{M}$. Figure 5 shows the injection in triplicate of the standard solutions and pharmaceutical preparations.

The results obtained were compared with those obtained by the reference methods, ${ }^{[8,9]}$ to evaluate the accuracy of these techniques. 
Table 3. Determination of dihydrocodeine in commercial pharmaceutical formulations using the square wave voltammetric method (SWV), FIA with electrochemical detection (FIA-EC) and reference methods.

\begin{tabular}{|c|c|c|c|c|}
\hline Formulation & $\begin{array}{l}\text { Dihydrocodeine } \\
\text { nominal content }\end{array}$ & $\mathrm{SWV}^{\mathrm{a}}$ & FIA-EC & $\begin{array}{l}\text { Reference } \\
\text { method }^{\mathrm{a}}\end{array}$ \\
\hline Didor Continus ${ }^{\circledR}$ & $60 \mathrm{mg} /$ tablet & $59.9 \pm 0.3$ & $60.5 \pm 0.3$ & $60.1 \pm 0.5$ \\
\hline$t^{\mathrm{b}}$ & & 0.5 & 0.4 & \\
\hline$F^{\mathrm{c}}$ & & 2.8 & 2.8 & \\
\hline Paracodina $^{\circledR}$ & $10 \mathrm{mg} /$ tablet & $10.2 \pm 0.3$ & $10.1 \pm 0.2$ & $10.1 \pm 0.4$ \\
\hline$t^{\mathrm{b}}$ & & 0.7 & 0.4 & \\
\hline$F^{\mathrm{c}}$ & & 1.8 & 4.0 & \\
\hline Paracodina $N^{\circledR}$ & $12 \mathrm{mg} / 5 \mathrm{~mL}$ & $11.8 \pm 0.2$ & $12.1 \pm 0.2$ & $11.9 \pm 0.1$ \\
\hline$t^{\mathrm{b}}$ & & 0.8 & 0.3 & \\
\hline$F^{\mathrm{c}}$ & & 4.0 & 4.0 & \\
\hline
\end{tabular}

${ }^{\mathrm{a}}$ Mean and standard deviations of five determinations ( $\mathrm{mg} /$ tablet or $\mathrm{mg} / 5 \mathrm{~mL}$ ).

${ }^{\mathrm{b}}$ Tabulated $t$-value for $P=0.05$ and eight degrees of freedom is 2.306 .

${ }^{\mathrm{c}}$ Tabulated $F$-value for $P=0.05$ and $f_{1}=f_{2}=4$ is 6.39 .

Table 3 lists the mean results obtained for five replicate determinations of the pharmaceutical preparations tested. The results obtained were compared statistically by Student's $t$-test and Variance ratio $F$-test (Table 3 ). The experimental values did not exceed the theoretical values in either tests, which indicates that there was no significant difference between the methods compared.

\section{CONCLUSIONS}

The electrochemical methodologies developed are shown to be valuable for the determination of dihydrocodeine with good accuracy and precision. They show a similar reproducibility to the official methods but they are faster and cheaper than those employed in pharmaceutical analytical control laboratories. In particular, the flow injection system enables the determination of dihydrocodeine in pharmaceutical preparations at a rate of 115 samples per hour.

Complex pretreatment of the samples is avoided since the preparation of the pharmaceutical preparations simply involves dissolution in an electrolyte. The results obtained therefore suggest that these methods could replace time-consuming and costly procedures and could be easily used in quality control processes. 


\section{ACKNOWLEDGMENTS}

We thank Knoll Lusitana (Prior Velho, Portugal) for the generous gift of dihydrocodeine. One of us (J.M.P.J.G.) would like to thank the PRODEP Program for a Ph.D. grant.

\section{REFERENCES}

1. World Health Organization, Cancer Pain Relief, Geneva: WHO, 1986; 16.

2. Hofmann, U.; Fromm, M.F.; Johnson, S.; Mikus, G. Simultaneous determination of dihydrocodeine and dihydromorphine in serum by gas chromatography-tandem mass spectrometry. J. Chromatogr. B 1995, 663, 59-65.

3. Mykkanen, S.; Seppala, J.; Ariniemi, K.; Lillsunde, P. GCD quantitation of opiates as propionyl derivatives in blood. J. Anal. Toxicol. 2000, 24, 122-126.

4. Ohno, M.; Shiono, Y.; Konishi, M. Simultaneous determination of dihydrocodeine and its metabolites in dog plasma by highperformance liquid chromatography with electrochemical and ultraviolet detection. J. Chromatogr. B 1994, 654, 213-219.

5. Kirkwood, L.C.; Nation, R.L.; Somogyi, A.W. Determination of the dihydrocodeine metabolites, dihydromorphine and nordihydrocodeine in hepatic microsomal incubations by high-performance liquid chromatography. J. Chromatogr. B 1997, 701, 129-134.

6. Wey, A.B.; Caslavska, J.; Thormann, W. Analysis of codeine, dihydrocodeine and their glucuronides in human urine by electrokinetic capillary immunoassays and capillary electrophoresis-ion trap mass spectrometry. J. Chromatogr. A 2000, 895, 133-146.

7. Colbert, D.L.; Gooch, J.C. An in-house opiate enzymoimmunoassay based on the syva emit principle. Clin. Chem. 1992, 38, 1483-1485.

8. British Pharmacopoeia, Stationery Office: London, 2000.

9. U.S. Pharmacopoeia, XXIV Ed.; United States Pharmacopeial Convention: Rockville, 2000.

10. Sakano, I.; Kokubo, S. Simultaneous determination of acetaminophen, caffeine and dihydrocodeine phosphate in tablets by highperformance liquid chromatography. Anal. Sci. 1989, 5, 623-624.

11. Masuda, M.; Satoh, T.; Handa, M.; Itoh, Y.; Sagara, K. Simultaneous determination of the components in an anti-cold drug by gradient HPLC. Bunseki Kagaku 1997, 46, 777-783. 
12. Bishop, E.; Hussein, W. Anodic voltammetry of codeine and dihydrocodeine at rotating disc electrodes of platinum and gold. Analyst 1984, 109, 143-145.

13. Alegret, S.; Alonso, J.; Bartroli, J.; Machado, A.A.S.C.; Lima, J.L.F.C.; Paulis, J.M. Construction of equipment for potentiometric determinations in flow injection analysis. Quim. Anal. 1987, 6, 278-294.

14. Metrohm, Electrochemical Detection in HPLC, Metrohm: Herisau, 1984.

15. Lima, J.L.F.C.; Rangel, A.O.S.S. Détermination spectrophotométrique du phosphore total et inorganique dans les vins par la technique d'injection dans un flux. J. Int. Sci. Vigne Vin 1990, 24, 49-61. 